Research Paper

\title{
Evaluation of a multiplex selective enrichment broth SEL for simultaneous detection of injured Salmonella, Escherichia coli O157:H7 and Listeria monocytogenes
}

\author{
Biao Suo ${ }^{1}$, Yuexia Wang ${ }^{2}$ \\ ${ }^{1}$ College of Food Science and Technology, Henan Agricultural University, China. \\ ${ }^{2}$ College of Life Sciences, Henan Agricultural University, China.
}

Submitted: December 27, 2011; Approved: November 13, 2012.

\begin{abstract}
Although many rapid and high throughput molecular methods have been developed in the recent years for the multiplex detection of foodborne pathogens, the simultaneous recovery and enrichment of sublethally injured cells is still a problem that needs to be considered. Combined with previous established multiplex real-time PCR assay, the capability of simultaneous recovery and enrichment of sublethally injured Salmonella, E. coli O157:H7 and L. monocytogenes cells was evaluated in a multiplex selective enrichment broth SEL. The injured cells were obtained by heat shock. After evaluation of different procedures, $1 \mathrm{~h}$ of recovery period prior to $20 \mathrm{~h}$ of enrichment was proved to be necessary for the detection of less than $10 \mathrm{CFU} / 5 \mathrm{~mL}$ broth of injured L. monocytogenes. When the detection method was applied to artificially contaminated ground beef, all the three injured pathogens could be simultaneously detected without discrimination by real-time PCR combined with SEL broth, the detection limit was $<5 \mathrm{CFU} / 10 \mathrm{~g}$ ground beef. Comparatively, when BPW was employed as the enrichment broth in the same detection procedure, injured L. monocytogenes could not be detected if the initially spiked level was below $10^{2} \mathrm{CFU} / 10 \mathrm{~g}$ ground beef. Considering the capability of co-enrichment and high detection effectiveness, the real-time PCR assay combined with SEL broth herein appears to be a promising tool for high-throughput screening of a large number of processed food samples, which require either single or multiple pathogen detection. More important, the sublethally injured foodborne pathogen cells were also detectable.
\end{abstract}

Key words: sublethal injury, SEL broth, multiplex detection, foodborne pathogen.

\section{Introduction}

Microbial foodborne pathogens are widespread and cause millions of cases of human illness every year around the world, with nearly a quarter of the population at higher

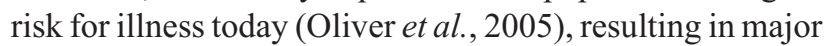
public health issues and substantial economic burden. Among the known pathogens, Salmonella spp., Escherichia coli $\mathrm{O} 157: \mathrm{H} 7$ and Listeria monocytogenes are important because of the severity of disease or the number of illness cases they cause (CDC, 2006). For the truth that many foods are common carriers of Salmonella spp., E. coli O157:H7 and L. monocytogenes, traditional pathogen detection has burdened the industry and regulatory agencies, for the testing of foods that have a high risk of contamina- tion with these pathogens (Nugen and Baeumner, 2008). Current research trends emphasize the development of multipathogen detection platforms in a single-assay format (Shi et al., 2010). The multipathogen detection approach is attractive and economically favorable since it can reduce labour requirement for handling a large number of samples, as well as reducing the overall cost of testing per pathogen.

Though the sensitivity of many multiplex detection methods have improved significantly, an enrichment step is still needed. This step is required not only to increase the target-pathogen concentration in a sample but also to resuscitate physiologically stressed or injured cells (Wu, 2008). Additionally, selective enrichment is also necessary to suppress the natural background microorganisms, to improve detection efficiency and to avoid false results. However, 
previously widely used broths for simultaneous enrichment of multiple pathogens before detection should belong to the nonselective media, such as buffered peptone water (BPW) (Alarcon et al., 2004; Wang and Suo, 2011), No. 17 medium (Kawasaki et al., 2010), universal pre-enrichment broth (UPB) (Bhagwat, 2003), et al. This kind of broth could recover and enrich target pathogens along with background flora, which was prone to cause false negative detection results, especially induced by the complex flora in tested food sample (Lindner et al., 2011). Although selective enrichment broth promises to avoid the interference of background flora in food samples, the drawbacks of previous selective enrichment broths are aimed to enrich one specular pathogen in one detection system, which was unsuitable for multiplex detection of one more pathogens. Moreover, the selective agents can be inhibitory or can delay the recovery and growth of healthy or stressed target pathogens (Jacobsen, 1999) and thus affecting the detection of pathogens by causing false negative results (Wu, 2008).

Therefore, a desired enrichment broth for multipathogen detection should have the capabilities of both recovery of sublethally injured cells and selective enrichment of target cells from complex background flora in food (Yu et al., 2010). SEL is a recently developed multiplex enrichment broth for simultaneously and selectively enrich Salmonella, E. coli O157:H7 and L. monocytogenes (Kim and Bhunia, 2008). So far, based on SEL broth, a multiplex real-time PCR (Suo et al., 2010b) and a microarray assays (Suo et al., 2010a) have been developed. Although SEL broth has been proven to be able to resuscitate acid- and cold-stressed cells preliminarily (Kim and Bhunia, 2008), its capability in simultaneous recovery and enrichment of stressed cells is still not confirmed thoroughly by low number and pure stressed cells, which might represent the real condition of multipathogens contamination in food.

\section{Materials and Methods}

\section{Bacterial strains and culture conditions}

The bacterial reference strains, including $S$. Typhimurium ATCC14028, E. coli O157:H7 ATCC43889 and L. monocytogenes CMCC54002 were obtained from the American Type Culture Collection (ATCC), or China Microbiological Culture Collection Center (CMCC). All strains were aerobically grown at $37{ }^{\circ} \mathrm{C}$ in Brain Heart Infusion medium (Becton Dickinson Co., Sparks, MD) shaking at $150 \mathrm{rpm}$. After overnight incubation from single colony, bacterial cells were collected for analysis.

\section{Preparation of sublethally injured bacterial cells}

One colony of each pathogen was inoculated in $5 \mathrm{~mL}$ of nutrient broth and cultivated to later exponential phase (cv. $10^{8} \mathrm{cfu} / \mathrm{mL}$, the growth curves of all tested pathogens were pre-determined). $0.5 \mathrm{~mL}$ of enriched broth was heat shocked in a preheated glass tube, and the survival curves were plotted according to the viable cells counts on differential plate. S. Typhimurium ATCC 14028 and E. coli O157:H7 ATCC43889 were heated at $55^{\circ} \mathrm{C}$, and $L$. monocytogenes CMCC54002 was heated at $60{ }^{\circ} \mathrm{C}$. Differential plate counting was performed in tryptic soy agar plus $0.6 \%$ yeast extract (TSAYE, from BD) for enumeration of total viable cells, and in TSAYE with $\mathrm{NaCl}$ (TSAYE-NA, $4 \% \mathrm{NaCl}$ for Salmonella and E. coli O157:H7, and 6\% $\mathrm{NaCl}$ for L. monocytogenes) for enumeration of uninjured cells only. Based on our pre-experiments, concentrations used to detect sublethal injury correspond to the highest $\mathrm{NaCl}$ concentrations that did not affect the growth of untreated cells (Suo et al., 2012). After 6 min of heat shock, each broth was serially 10 -fold diluted in $0.1 \%$ sterile peptone solution and used as sublethally injured cells. All sublethally injured cells were fresh prepared and used for the next enrichment experiment within $1 \mathrm{~h}$.

\section{Recovery of sublethally injured cells in SEL broth}

To optimize the condition for recovery of sublethally injured cells, for each pathogen, $100 \mu \mathrm{L}$ of serially diluted cell broth with known cell concentration were added to different $5 \mathrm{~mL}$ of Buffered Listeria Enrichment Broth Base (BLEB) (Becton Dickinson) and incubated at $37{ }^{\circ} \mathrm{C}$ with shaking at $150 \mathrm{rpm}$. After 0,1 and $2 \mathrm{~h}$ of incubations for each group, selective antibiotics were added to achieve final concentrations of $0.01 \mathrm{~g} / \mathrm{L}$ for Acriflavine (ICN Biomedical Inc., Aurora, OH), $0.05 \mathrm{~g} / \mathrm{L}$ for Cycloheximide, $0.05 \mathrm{~g} / \mathrm{L}$ for Fosfomycin, and $0.002 \mathrm{~g} / \mathrm{L}$ for Nalidixic acid (Sigma, St. Louis, MO) as described for SEL (Kim and Bhunia, 2008). Following by another $20 \mathrm{~h}$ of incubation, the cell number was counted by spreading on TSAYE and TSAYE-NA plates. All experiments were performed at least three times.

\section{Genomic DNA preparation and multiplex real-time PCR detection}

One $\mathrm{mL}$ of freshly grown bacterial culture was subjected to DNA extraction and purification using the DNeasy Blood \& Tissue kit (Qiagen, Valencia, CA) following the manufacturer's recommendations. Before DNA extraction, the cell pellets were digested in $180 \mu \mathrm{L}$ of $20 \mathrm{mg} / \mathrm{mL}$ lysozyme (containing $20 \mathrm{mM}$ Tis- $\mathrm{Cl}, \mathrm{pH}=8.0$, $2 \mathrm{mM}$ sodium EDTA and $1.2 \%$ Triton ${ }^{\circledR} \mathrm{X}-100$ ) at $37{ }^{\circ} \mathrm{C}$ for $30 \mathrm{~min}$. The primer and probe sets, multiplex real-time PCR procedure for the simultaneous detection and quantification of Salmonella spp., E. coli O157:H7 and L. monocytogenes were referred to Suo et al. (2010b), and performed on a 7500 Real-Time PCR system (Applied Biosystems, Foster City, CA).

\section{Application to artificially contaminated ground beef by sublethally injured cells}

Ground beef samples were artificially contaminated by seven different combinations of initial sublethally in- 
jured cell numbers to examine the simultaneous recovery and enrichment capability of each pathogen in SEL. Before spiking, the ground beef was confirmed by traditionally culture-based methods to be lacking the three target pathogens. $100 \mu \mathrm{L}$ of serial diluted later-exponential cell broth ranged from $10^{1} \mathrm{cfu} / \mathrm{mL}$ to $10^{4} \mathrm{cfu} / \mathrm{mL}$ were inoculated to $10 \mathrm{~g}$ of ground beef samples. The initial cell numbers before dilution were $3.3 \times 10^{8} \mathrm{cfu} / \mathrm{mL}$ for $S$. Typhimurium ATCC14028, $4.1 \times 10^{8} \mathrm{cfu} / \mathrm{mL}$ for E. coli $\mathrm{O} 157: \mathrm{H} 7$ ATCC43889 and $3.7 \times 10^{8} \mathrm{cfu} / \mathrm{mL}$ for L. monocytogenes CMCC54002. The final cell counts of the four combinations of injured pathogens in beef samples were: A, $10^{3}: 10^{3}: 10^{3}$; B, $10^{2}: 10^{2}: 10^{2}$; C, $10^{1}: 10^{1}: 10^{1}$; D, $10^{0}: 10^{0}: 10^{0}$; E, $10^{3}: 10^{0}: 10^{1}$; F, $10^{0}: 10^{1}: 10^{3}$; and $\mathrm{G}, 10^{1}: 10^{3}: 10^{0}$, respectively. All samples were put into a filter stomacher bag (Nasco Whirl-Pak, Fort Atkinson, WI) before adding 90 $\mathrm{mL}$ of BLEB broth. After $1 \mathrm{~h}$ of incubation at $37^{\circ} \mathrm{C}$, selective antibiotics were added to obtain SEL broth as described above. After enrichment under the same conditions for $20 \mathrm{~h}, 1 \mathrm{~mL}$ aliquot was collected from each sample for DNA extraction and quantitative real-time PCR determination. As comparisons, the same artificially contaminated beef samples were also recovered and enriched by a nonselective universal enrichment buffered peptone water (BPW) for $20 \mathrm{~h}$. These experiments were repeated three times with two replicates per trial.

\section{Results and Discussion}

Heat injury of Salmonella, E. coli O157:H7 and L. monocytogenes

Before the thermal injury experiment, newly cultivated cells of $S$. Typhimurium ATCC14028, E. coli O157:H7 ATCC43889 and L. monocytogenes CMCC54002 on later exponential phase were sprayed on TSAYE agars plus increasing concentration of $\mathrm{NaCl}$ ranged from $0 \%$ to $10 \%$, respectively, which was to determine the most tolerance of these pathogens. According to the results, the difference of cell counts was not significant between the sprayed results on TSAYE and TSAYE-NA, until the concentration of $\mathrm{NaCl}$ was increased to $6 \%$ for L. monocytogenes, and $4 \%$ for Salmonella and E. coli O157:H7 (data no presented). Thus, the concentrations were considered as the most tolerant to $\mathrm{NaCl}$ and were used to count noninjured number of these pathogens, respectively.

Before sublethally injured cells obtainment, Salmonella, E. coli $\mathrm{O} 157: \mathrm{H} 7$ and L. monocytogenes were mild heated under the same condition $\left(55{ }^{\circ} \mathrm{C}\right)$, the $L$. monocytogenes cells showed a greater thermal stress resistance. This was expressed by both lower rate of lethality and less than $1 \log _{10} \mathrm{cfu} / \mathrm{mL}$ difference in the number between survivors on TSAYE and selective TSAYE-NA (data not presented), which was coincident with previous comparative results of the same three pathogens (Juneja, 2003). In this case, a higher temperature of $60^{\circ} \mathrm{C}$ was im- posed on L. monocytogenes to obtain the thermal injured cells. As results shown in Figure 1, after 6 min of heat treatment, at least $3 \log _{10} \mathrm{cfu} / \mathrm{mL}$ difference of viable cells were counted on differential plates, indicated more than 99.9 percent of survival cells were sublethally injured (Wesche et al., 2009).


Figure 1 - Thermal sublethal injury of Salmonella (A), E. coli O157:H7 (B) and L. monocytogenes (C) cells in nutrient broth. Cells were heated under $60{ }^{\circ} \mathrm{C}$ for L. monocytogenes and $55^{\circ} \mathrm{C}$ for Salmonella and E. coli O157:H7. • number of total viable cells counted on TSAYE; ${ }^{\circ}$, number of uninjured cells counted on TSAYE-NA. 


\section{Evaluation of the recovery of sublethally injured cells in SEL}

To simplify the operation steps and minimize the possibility of cross-contamination during enrichment of multiplex pathogens, a new enrichment procedure was designed and evaluated for the capability of recovery and enrichment of sublethally injured Salmonella, E. coli $\mathrm{O} 157: \mathrm{H} 7$ and $L$. monocytogenes. The enrichment procedure was imitated the selective enrichment step in FDA recommended BAM method for detection of L. monocytogenes (BAM, 2011). With the purpose of shortening the enrichment period as much as possible, $0,1,2 \mathrm{~h}$ of periods were compared by the recovery effect of sublethally injured cells in nonselective BLEB broth. As shown in Table 1, the $100 \mu \mathrm{L}$ of initially spiked cell number in $5 \mathrm{~mL}$ BLEB broth could only be detected viable cells on nonselective TSAYE agars but could not on selective TSAYE-NA agars, which indicated that the spiked cells were all sublethally injured (Aljarallah and Adams, 2007; Jofre et al., 2010; Saldana et al., 2010).

Table 1 - Result of recovery and enrichment of thermal injured cells in SEL broth.

\begin{tabular}{|c|c|c|c|c|c|}
\hline \multirow[t]{2}{*}{ Strains } & \multicolumn{2}{|c|}{ Spiked cells (cfu/5 mL BLEB) } & \multirow[t]{2}{*}{ Recovery time (h) } & \multicolumn{2}{|c|}{ Cells after $20 \mathrm{~h}$ enrichment $(\mathrm{cfu} / \mathrm{mL})$} \\
\hline & TSAYE & TSAYE-NA & & TSAYE & TSAYE-NA \\
\hline \multirow[t]{12}{*}{$S$. Typhimurium } & $1.80 \times 10^{2}$ & $0^{*}$ & 0 & $3.70 \times 10^{9}$ & $2.86 \times 10^{9}$ \\
\hline & $1.80 \times 10^{1}$ & 0 & 0 & $2.15 \times 10^{9}$ & $1.98 \times 10^{9}$ \\
\hline & $1.80 \times 10^{0}$ & 0 & 0 & $1.44 \times 10^{9}$ & $1.39 \times 10^{9}$ \\
\hline & 0 & 0 & 0 & 0 & 0 \\
\hline & $1.80 \times 10^{2}$ & 0 & 1 & $5.95 \times 10^{9}$ & $5.70 \times 10^{9}$ \\
\hline & $1.80 \times 10^{1}$ & 0 & 1 & $5.03 \times 10^{9}$ & $4.49 \times 10^{9}$ \\
\hline & $1.80 \times 10^{0}$ & 0 & 1 & $4.00 \times 10^{9}$ & $3.97 \times 10^{9}$ \\
\hline & 0 & 0 & 1 & 0 & 0 \\
\hline & $1.80 \times 10^{2}$ & 0 & 2 & $6.72 \times 10^{9}$ & $6.29 \times 10^{9}$ \\
\hline & $1.80 \times 10^{1}$ & 0 & 2 & $6.19 \times 10^{9}$ & $5.90 \times 10^{9}$ \\
\hline & $1.80 \times 10^{0}$ & 0 & 2 & $5.28 \times 10^{9}$ & $5.47 \times 10^{9}$ \\
\hline & 0 & 0 & 2 & 0 & 0 \\
\hline \multirow[t]{12}{*}{ E. coli $\mathrm{O} 157: \mathrm{H} 7$} & $2.00 \times 10^{2}$ & 0 & 0 & $3.27 \times 10^{9}$ & $1.58 \times 10^{9}$ \\
\hline & $2.00 \times 10^{1}$ & 0 & 0 & $4.16 \times 10^{9}$ & $2.10 \times 10^{9}$ \\
\hline & $2.00 \times 10^{0}$ & 0 & 0 & $1.65 \times 10^{9}$ & $1.08 \times 10^{9}$ \\
\hline & 0 & 0 & 0 & 0 & 0 \\
\hline & $2.00 \times 10^{2}$ & 0 & 1 & $4.40 \times 10^{9}$ & $3.77 \times 10^{9}$ \\
\hline & $2.00 \times 10^{1}$ & 0 & 1 & $3.99 \times 10^{9}$ & $3.29 \times 10^{9}$ \\
\hline & $2.00 \times 10^{0}$ & 0 & 1 & $2.22 \times 10^{9}$ & $2.01 \times 10^{9}$ \\
\hline & 0 & 0 & 1 & 0 & 0 \\
\hline & $2.00 \times 10^{2}$ & 0 & 2 & $4.78 \times 10^{9}$ & $3.96 \times 10^{9}$ \\
\hline & $2.00 \times 10^{1}$ & 0 & 2 & $4.21 \times 10^{9}$ & $4.07 \times 10^{9}$ \\
\hline & $2.00 \times 10^{0}$ & 0 & 2 & $2.38 \times 10^{9}$ & $2.15 \times 10^{9}$ \\
\hline & 0 & 0 & 2 & 0 & 0 \\
\hline \multirow[t]{12}{*}{ L. monocytogenes } & $8.80 \times 10^{2}$ & 0 & 0 & $2.12 \times 10^{9}$ & $1.56 \times 10^{9}$ \\
\hline & $8.80 \times 10^{1}$ & 0 & 0 & $1.22 \times 10^{9}$ & $1.29 \times 10^{9}$ \\
\hline & $8.80 \times 10^{0}$ & 0 & 0 & 0 & 0 \\
\hline & 0 & 0 & 0 & 0 & 0 \\
\hline & $8.80 \times 10^{2}$ & 0 & 1 & $2.63 \times 10^{9}$ & $2.33 \times 10^{9}$ \\
\hline & $8.80 \times 10^{1}$ & 0 & 1 & $1.85 \times 10^{9}$ & $2.65 \times 10^{9}$ \\
\hline & $8.80 \times 10^{0}$ & 0 & 1 & $1.95 \times 10^{8}$ & $2.48 \times 10^{8}$ \\
\hline & 0 & 0 & 1 & 0 & 0 \\
\hline & $8.80 \times 10^{2}$ & 0 & 2 & $3.86 \times 10^{9}$ & $3.86 \times 10^{9}$ \\
\hline & $8.80 \times 10^{1}$ & 0 & 2 & $1.67 \times 10^{9}$ & $1.08 \times 10^{9}$ \\
\hline & $8.80 \times 10^{0}$ & 0 & 2 & $4.20 \times 10^{8}$ & $3.11 \times 10^{8}$ \\
\hline & 0 & 0 & 2 & 0 & 0 \\
\hline
\end{tabular}

* $0 \mathrm{cfu} / \mathrm{mL}$ represented non viable cells could be detected in $100 \mu \mathrm{L}$ of broth. 
The recovery and enrichment results of sublethally injured pathogens in SEL were shown in Table 1, $S$. Typhimurium and E. coli $\mathrm{O} 157: \mathrm{H} 7$ both could be reached to the level of $10^{9} \mathrm{cfu} / \mathrm{mL}$ after $20 \mathrm{~h}$ of selective enrichment, even when only $2 \mathrm{cfu}$ of cells were inoculated initially in $5 \mathrm{~mL}$ of BLEB broth, and no matter whether had passed 1,2 $\mathrm{h}$ of recovery periods or not. However, L. monocytogenes showed a lower growth rate and less recovery capability in SEL plus antibiotics. Only the level of $10^{8} \mathrm{cfu} / \mathrm{mL}$ viable cells could be detected on TSAYE and TSAYE-NA agars when $<10$ cfu of sublethally injured cells were initially inoculated. Moreover, under this inoculation level, no viable cell was shown on plates after $20 \mathrm{~h}$ of selective enrichment without pre-recovery period. This inhibition might be attributed to the susceptibility of membrane injured L. monocytogenes cells to the antibiotics in SEL, thus these cells would be inactivated if without enough recovery period was imposed (Jacobsen, 1999). For this reason, 1 h of nonselective recovery period before $20 \mathrm{~h}$ of selective enrichment step was chosen for following multiplex real-time PCR detection.

\section{Evaluation of SEL in artificially contaminated food}

BPW was a commonly used enrichment broth that has been widely applied to recover and enrich sublethally injured cells in USDA/FSIS recommended methods for many foodborne pathogens detections (USDA/FSIS Microbiology Laboratory Guidebook), as well as it is a generally recommended nonselective media, in which the three bacteria are able to grow (Alarcon et al., 2004). Since the complex background flora in food could also be enriched along with detection target pathogens in these kinds of nonselective both, which were tended to cause false negative/positive detection results, selective enrichment has been considered as a necessary step before molecular detection procedure (Kim and Bhunia, 2008).

In present research, seven different combinations of sublethally injured Salmonella, E. coli O157:H7 and L. monocytogenes in spiked beef were used to compare the capability of SEL and BPW in simultaneous recovery and enrichment of injured cells. As results shown in Table 2 calculated from the cycle threshold $(\mathrm{Ct})$ value by amplification standard curve of quantitative real-time PCR, when BPW was used for the simultaneous enrichment of the three foodborne pathogens, for Salmonella and E. coli O157:H7, lower cell numbers ranged from 0 to $2 \log _{10}$ genome copy $/ \mathrm{mL}$ were determined in BPW than that in SEL. The growth of $L$. monocytogenes was much more suppressed by $5 \sim 6 \log _{10}$ genome copy $/ \mathrm{mL}$ when other two pathogens existed in BPW broth. Evenly, when the initially spiked level was below $10^{2} \mathrm{cfu} / 10 \mathrm{~g}$ ground beef, no positive genome copy of $L$. monocytogenes could be detected by multiplex real-time PCR.

Comparatively, when the same combinations of three foodborne pathogens were inoculated in SEL broth, all the three target pathogens could be simultaneously detected at a detection limit of $<5 \mathrm{cfu} / 10 \mathrm{~g}$ ground beef, after $1 \mathrm{~h}$ of recovery and $20 \mathrm{~h}$ of selective enrichment periods, no matter in each combination of pathogens. The detection limit was comparable to the previously reported real-time PCR assays for the detection of inoculated healthy cells (Kawasaki et al., 2010; Suo et al., 2010b). Althoug $\log _{10} 1 \sim 4$ genome copy/mL lower was observed on L. monocytogenes compared to Salmonella and E. coli O157:H7, indicated the growth of L. monocytogenes was still partially competitively inhibited by other bacteria, this inhibition was comparable to optimized No. 17 broth without dextrose and was considered as not influence on the obtainment of positive detection results by real-time PCR assays (Omiccioli et al., 2009).

In terms of detection speed of multiple pathogens, the entire process of the multiplex assay from sample enrichment to data analysis can be completed within $24 \mathrm{~h}$. The positive detection results could be obtained when either healthy or sublethally injured cells existed in food samples with complex background microflora. The effectiveness of the detection was significantly improved from traditional culturing methods, which require 5-7 days to analyze a single species (Jasson et al., 2010).

\section{Conclusion}

In conclusion, sublethally injured cells of Salmonella, E. coli $\mathrm{O} 157$ and L. monocytogenes were obtained by heat

Table 2 - Comparisons of simultaneous recovery and enrichment of sublethally injured Salmonella, E. coli O157:H7 and L. monocytogenes in SEL and BPW broth using multiplex real-time PCR method in spiked ground beef.

\begin{tabular}{|c|c|c|c|c|c|c|}
\hline \multirow{2}{*}{$\begin{array}{l}\text { Pathogens mixture of Salmonella, E. coli } \mathrm{O} 157: \mathrm{H} 7 \\
\text { and L. monocytogenes (cfu/10 g ground beef) }\end{array}$} & \multicolumn{3}{|c|}{ Recovery and enrichment in SEL } & \multicolumn{3}{|c|}{ Recovery and enrichment in BPW } \\
\hline & $\operatorname{inv} A$ & $r f b E$ & hlyA & invA & $r f b E$ & hlyA \\
\hline $10^{3}: 10^{3}: 10^{3}$ & $1.83 \times 10^{8}$ & $7.91 \times 10^{8}$ & $6.69 \times 10^{7}$ & $9.91 \times 10^{7}$ & $9.26 \times 10^{7}$ & $2.30 \times 10^{1}$ \\
\hline $10^{2}: 10^{2}: 10^{2}$ & $1.39 \times 10^{8}$ & $9.10 \times 10^{8}$ & $3.21 \times 10^{7}$ & $8.28 \times 10^{6}$ & $6.25 \times 10^{7}$ & $1.73 \times 10^{0}$ \\
\hline $10^{1}: 10^{1}: 10^{1}$ & $8.89 \times 10^{7}$ & $9.23 \times 10^{8}$ & $5.66 \times 10^{6}$ & $8.12 \times 10^{6}$ & $8.29 \times 10^{6}$ & - \\
\hline $10^{0}: 10^{0}: 10^{0}$ & $6.64 \times 10^{7}$ & $9.27 \times 10^{8}$ & $4.23 \times 10^{5}$ & $6.17 \times 10^{6}$ & $5.61 \times 10^{6}$ & - \\
\hline $10^{3}: 10^{0}: 10^{1}$ & $6.51 \times 10^{8}$ & $2.47 \times 10^{7}$ & $4.07 \times 10^{5}$ & $6.61 \times 10^{8}$ & $4.58 \times 10^{6}$ & - \\
\hline $10^{0}: 10^{1}: 10^{3}$ & $2.09 \times 10^{7}$ & $3.62 \times 10^{8}$ & $5.29 \times 10^{6}$ & $4.21 \times 10^{6}$ & $6.56 \times 10^{6}$ & $4.51 \times 10^{1}$ \\
\hline $10^{1}: 10^{3}: 10^{0}$ & $6.43 \times 10^{7}$ & $2.29 \times 10^{9}$ & $1.48 \times 10^{5}$ & $7.28 \times 10^{7}$ & $5.33 \times 10^{8}$ & - \\
\hline
\end{tabular}


shock, and their capability of simultaneous recovery and enrichment in SEL was evaluated in present research. After evaluation of different enrichment procedure, $1 \mathrm{~h}$ of recovery before $20 \mathrm{~h}$ of enrichment period is necessary for the detection of less than $10 \mathrm{cfu}$ of all the sublethally injured target cells. Considering the capability of anti-competitive growth inhibition and high effectiveness, the real-time PCR assay combined with SEL selective enrichment broth herein appears to be a promising tool for high-throughput screening of a large number of thermal processed food samples, which require either single or multiple pathogen detection but sublethally injured cells probably existed.

\section{Acknowledgments}

This study was financially supported by the National Natural Science Foundation of China (grant no. U1204331), the Science and Technology Department of Henan Province (grant no. 122102310310), the Education Department of Henan Province (grant no. 13A550486) and the Start-up Funding, Dr. of Henan Agricultural University (grant no. 30300168).

\section{References}

Alarcon B, Garcia-Canas V, Cifuentes A, Gonzalez R, Aznar R (2004) Simultaneous and sensitive detection of three foodborne pathogens by multiplex PCR, capillary gel electrophoresis, and laser-induced fluorescence. J Agric Food Chem 52:7180-7186.

Aljarallah KM, Adams MR (2007) Mechanisms of heat inactivation in Salmonella serotype Typhimurium as affected by low water activity at different temperatures. J Appl Microbiol 102:153-160.

BAM (2011) Detection and enumeration of Listeria monocytogenes. In FDA Bacteriological Analytical Manual (online). Available from http://www.fda.gov/food/ scienceresearch/laboratorymethods/bacteriologicalanalytic almanualbam/ucm071400.htm (April 2011).

Bhagwat AA (2003) Simultaneous detection of Escherichia coli O157:H7, Listeria monocytogenes and Salmonella strains by real-time PCR. Int J Food Microbiol 84:217-224.

Centers for Disease Control and Prevention (2006) Preliminary FoodNet data on the incidence of infection with pathogens transmitted commonly through food - 10 states, United States, 2005. Morb. Mortal. Wkly. Rep. 55:392-395.

Jacobsen CN (1999) The influence of commonly used selective agents on the growth of Listeria monocytogenes. Int J Food Microbiol 50:221-226.

Jasson V, Jacxsens L, Luning P, Rajkovic A, Uyttendaele M (2010) Alternative microbial methods: An overview and selection criteria. Food Microbiol 27:710-730.

Jofre A, Aymerich T, Bover-Cid S, Garriga M (2010) Inactivation and recovery of Listeria monocytogenes, Salmonella enterica and Staphylococcus aureus after high hydrostatic pressure treatments up to $900 \mathrm{MPa}$. Int Microbiol 13:105112.

Juneja VK (2003) A comparative heat inactivation study of indigenous microflora in beef with that of Listeria monocytogenes, Salmonella serotypes and Escherichia coli O157:H7. Lett Appl Microbiol 37:292-298.

Kawasaki S, Fratamico PM, Horikoshi N, Okada Y, Takeshita K, Sameshima T, Kawamoto S (2010) Multiplex real-time polymerase chain reaction assay for simultaneous detection and quantification of Salmonella species, Listeria monocytogenes, and Escherichia coli O157:H7 in ground pork samples. Foodborne Pathog Dis 7:1-6.

Kim H, Bhunia AK (2008) SEL, a selective enrichment broth for simultaneous growth of Salmonella enterica, Escherichia coli O157:H7, and Listeria monocytogenes. Appl Environ Microbiol 74:4853-4866.

Lindner JDD, Santarelli M, Yamaguishi CT, Soccol CR, Neviani E (2011) Recovery and identification of bovine colostrum microflora using traditional and molecular approaches. Food Technol Biotechnol 49:364-368.

Nugen SR, Baeumner AJ (2008) Trends and opportunities in food pathogen detection. Anal Bioanal Chem 391:451-454.

Oliver SP, Jayarao BM, Almeida RA (2005) Foodborne pathogens in milk and the dairy farm environment: food safety and public health implications. Foodborne Pathog Dis 2:115-129.

Omiccioli E, Amagliani G, Brandi G, Magnani M (2009) A new platform for Real-Time PCR detection of Salmonella spp., Listeria monocytogenes and Escherichia coli $\mathrm{O} 157$ in milk. Food Microbiol 26:615-622.

Saldana G, Puertolas E, Condon S, Alvarez I, Raso J (2010) Modeling inactivation kinetics and occurrence of sublethal injury of a pulsed electric field-resistant strain of Escherichia coli and Salmonella Typhimurium in media of different pH. Innov Food Sci Emerg Technol 11:290-298.

Shi XM, Long F, Suo B (2010) Molecular methods for the detection and characterization of foodborne pathogens. Pure Appl Chem 82:69-79.

Suo B, He Y, Paoli G, Gehring A, Tu SI, Shi X (2010a) Development of an oligonucleotide-based microarray to detect multiple foodborne pathogens. Mol Cell Probes 24:77-86.

Suo B, He Y, Tu SI, Shi X (2010b) A multiplex real-time polymerase chain reaction for simultaneous detection of Salmonella spp., Escherichia coli O157, and Listeria monocytogenes in meat products. Foodborne Pathog Dis 7:619-628.

Suo B, Shi C, Shi X (2012) Inactivation and occurrence of sublethal injury of Salmonella Typhimurium under mild heat stress in broth. J Verbr Lebensm 7:125-131.

Wang Y, Suo B (2011) A new 7-plex PCR assay for simultaneous detection of shiga toxin-producing Escherichia coli $\mathrm{O} 157$ and Salmonella Enteritidis in meat products. J Verbr Lebensm 6:441-447.

Wesche AM, Gurtler JB, Marks BP, Ryser ET (2009) Stress, sublethal injury, resuscitation, and virulence of bacterial foodborne pathogens. J Food Prot 72:1121-1138.

Wu VC (2008) A review of microbial injury and recovery methods in food. Food Microbiol 25:735-744.

Yu YG, Wu H, Liu YY, Li SL, Yang XQ, Xiao XL (2010) A multipathogen selective enrichment broth for simultaneous growth of Salmonella enterica serovar Enteritidis, Staphylococcus aureus, and Listeria monocytogenes. Can J Microbiol 56:585-597.

All the content of the journal, except where otherwise noted, is licensed under a Creative Commons License CC BY-NC. 